\title{
RECENT JUDICIAL DEVELOPMENTS OF INTEREST TO OIL AND GAS LAWYERS \\ WHITE RESOURCE MGMT. LTD. v. DURISH
}

The following comment appeared at page 371 of the Alberta Law Review Petroleum Law Edition Volume XXX, Number 1 (February 1992) in an article co-authored by Edward A. Leew and Michael A. Thackray entitled "Recent Judicial Developments of Interest to Oil and Gas Lawyers" in the context of a case comment on White Resource Mgmt. Ltd v. Durish (1991), 77 Alta L.R. (2d) 131 (Alta Q.B.):

In short, the writers would have to suggest that because of the factual circumstances in this case (Mr. Durish clearly did not come with clean hands and was arguably motivated by greed), the court in no way wanted to find in his favour...

The authors of the article acknowledge that their reference to the "factual circumstances" and their conclusion as to the motivation of the court reflect only their speculation as to the possible facts and rationale underlying a decision which they felt could not be explained on the basis of the law alone. In that sense, the authors and Macleod Dixon consider their words to represent fair comment with regard to that decision. No suggestion that Mr. Durish's character or behaviour did or should have influenced the court in its decision was intended by these speculations of the authors.

The authors and Macleod Dixon, who are familiar with both Mr. Durish and the facts of the case, hold no unfavourable personal view regarding Mr. Durish's character or motive and do not doubt his personal integrity.

The authors, Macleod Dixon, the Canadian Petroleum Law Foundation and the Alberta Law Review apologize to Mr. Durish for any inference or suggestion to the contrary which was or might be drawn from the comment and for any inadvertent insult or embarrassment to him. 